\title{
Sources of moisture for China and their variations during drier and wetter conditions in 2000-2004: a Lagrangian approach
}

\author{
Anita Drumond*, Raquel Nieto, Luis Gimeno \\ EPhysLab, Departamento de Física Aplicada, Facultade de Ciencias, Universidade de Vigo, Ourense, Spain
}

\begin{abstract}
We provide an overview of the sources of moisture that affect the major regimes of precipitation in China during the extended boreal summer (from April to September), as well as some indication of the variations in these sources during drier and wetter conditions. The Lagrangian FLEXPART model was used to identify the contributions of humidity to the moisture budget in a region by computing the changes in specific humidity along the backward trajectories of air masses for the previous $10 \mathrm{~d}$. We carried out analyses for 2000 to 2004 and identified those years that had the highest and lowest average rates of precipitation in 13 different regions in China, each of which is characterised by different regimes in terms of precipitation. Although the period of the study was relatively short, the results suggest that the contributions of moisture from the East and South China Seas are significant for precipitation in the eastern and southeastern coastal areas, while the Arabian Sea and the Bay of Bengal are important sources of moisture for the southern and central regions of China. Moreover, the northern regions receive some moisture from western Asia. Our analysis of wetter and drier years suggests that, in general, a more unstable atmosphere prevailed over the different target areas during all wetter periods considered.
\end{abstract}

KEY WORDS: Sources of moisture $\cdot$ Lagrangian approaches $\cdot$ Precipitation $\cdot$ China $\cdot$ FLEXPART

\section{INTRODUCTION}

The distribution of rainfall in China varies significantly as a result of complex terrain and the seasonal progress of the East Asian monsoon, which usually causes significant drought and flood events in many different parts of China (Chen et al. 2009). Larger amounts of precipitation are generally observed in southern and coastal regions, while rather less precipitation occurs in the northern and inland regions (Chen et al. 2009). In seasonal terms, the belt of rainfall moves gradually from south to north with the advance of the monsoon, and brings hot and humid conditions to eastern China between the months of May and August, after which it retreats southwards between late summer and autumn (Tao \& Chen 1987, Ding 1992, Lau \& Yang 1997). How- ever, neither the seasonal advance nor the retreat of precipitation is observed in western China (Qian \& Qin 2008). Because the rainy season is associated mainly with the seasonal migration of a belt of rainfall, it occurs during late spring and early summer in southern China, while the dominant rainy season occurs in mid to late summer in northern China, and during the summer in west-central China (Chen et al. 2009). The retarding and deflecting effects of the Tibetan Plateau in winter and spring generate an asymmetric, dipole zonal-deviation circulation, with a large anticyclone gyre to the north and a cyclonic gyre to the south. Such a dipole deviation circulation enhances the cold outbreaks from the north over eastern Asia, results in a dry climate in southern Asia and a moist climate over the Indochina peninsula and southern China and forms the persis- 
tent rainfall in early spring in southern China (Wu et al. 2007).

A number of studies have been conducted with the aim of identifying the regimes of precipitation in China in order to understand the influence of the interactions between large-scale circulation and regional processes on the distribution of precipitation (e.g. China Meteorological Center 1979, Ronberg \& Wang 1987, Wang et al. 1998, Qian et al. 2003, Sun et al. 2005, Ren et al. 2006, Qian \& Qin 2008). However, some discrepancies among the findings of some of these studies are apparent, owing to their use of different data sets, geographical domains, periods and statistical approaches. More recently, in their search for regional indices of precipitation that could be used in statistical forecast models, Chen et al. (2009) mapped the regimes of precipitation of China by using empirical orthogonal function analysis with orthogonal rotation applied over normalised monthly mean precipitation data obtained from 400 stations between 1961 and 2006. These investigators defined the regional boundaries by using the approach of maximum loading, and by focusing on variations in seasonal and interannual precipitation, they identified a total of 13 dominant regional patterns of precipitation. On the interannual time scale, the summer rainfall pattern in China features a tripole structure on both the zonal and meridional directions (Huang et al. 2011a,b). However, the rainfall variability mode has changed from the typical tripole to dipole structure since the early 1990s, and is now characterised by a significant decrease in summer rainfall over a large part of northern and northeastern China (Liu et al. 2011) and by an increase of precipitation over southern China (Huang et al. 2011b).

In addition to identifying the regional patterns, it is important to identify the sources of moisture that affect a particular region in order to gain a better understanding of a given regime of precipitation and its temporal variability. It is now commonly accepted that the precipitation that falls in a region has one of 3 origins (Brubaker et al. 1993), namely (1) moisture that is already present in the atmosphere, (2) moisture that has been transported into the region from remote sources by wind (advection) and (3) local evaporation from the earth's surface (recycling). Although its definition varies, recycling is commonly defined to refer to that part of the water that evaporates from a given area and that contributes to the precipitation in that same area (e.g. Eltahir \& Bras 1996). According to Trenberth et al. (2003), the contribution of moisture already present in the atmosphere is negligible when averaged over long periods. Hence, the ob- served atmospheric moisture in a given region is present mainly because of advection and recycling.

Although a number of different approaches may be used to identify geographical sources of moisture, they all suffer from some kind of drawback. The approaches used may be grouped into 4 categories: (1) studies in which recycling ratios are calculated (e.g. Eltahir \& Bras 1996, Trenberth 1999), the main limitation of which is that the specific origin of the nonlocal water cannot be determined; (2) studies that use general circulation models and tracers of water vapour to assess the contributions of the major sources of evaporation to precipitation in a given region (e.g. Numaguti 1999, Bosilovich et al. 2003), in which the source regions must be specified and the quality of the results depends on the quality of the modelled data; (3) studies in which the atmospheric fluxes of moisture are integrated across regional boundaries (e.g. Chen et al. 1994, Fernandez et al. 2003, Liu \& Stewart 2003), which (like Category 1) also fail to provide information on the geographical sources of the moisture concerned; (4) studies that quantify the transport by using the specific trajectories of the moisture of interest (e.g. Crimp \& Mason 1999, Knippertz \& Martin 2005). The results of this last type of study can provide full 3-dimensional details of the origin of the air mass concerned, but do not take into account any increase or decrease of moisture along the trajectories that could affect precipitation in the target region.

In addition to the foregoing types of models, more appropriate and more sophisticated approaches have recently been developed that make use of the full kinematic trajectories calculated with different Lagrangian particle models. In a recent work, Gustafsson et al. (2010) investigated the atmospheric transport of moisture leading to extreme summer precipitation events in southern Sweden using a Lagrangian trajectory model. The methodology of Stohl \& James (2004, 2005) applied in our work determines the net changes in moisture along a large number of back trajectories, which then enables inferences to be made about the sources of moisture in a particular region.

In the belief that a Lagrangian approach can offer a more precise description of the trajectories of the air masses compared with more traditional Eulerian techniques, the aims of the present study are to provide an overview of the sources of moisture that affect the major regimes of precipitation in China, and to provide some indication of the variations in these sources between wetter and drier conditions selected during the period from 2000 to 2004 . We classified the regions according to the work of Chen et al. 
(2009). In our methodology, the 'sources of moisture' are defined to be those regions that are crossed by the air masses during their transit towards the target area, in which evaporation exceeds precipitation. Moreover, all the air masses identified in each target region, even the nonprecipitating ones, are tracked back to their origins. The robustness of our approach has been previously demonstrated in the successful application of the data and the methodology to the study of the contribution of the major oceanic moisture sources to continental precipitation (Gimeno et al. 2010), as well as in regional analyses, including the study of the sources of moisture for the Sahel (Nieto et al. 2006) and the South American Monsoon System (Drumond et al. 2008).

\section{DATA AND METHODOLOGY}

To determine the sources of moisture for our study regions, we made use of the Lagrangian particle dispersion model FLEXPART, which was developed by Stohl \& James $(2004,2005)$. This model uses data from the meteorological analysis of the European Centre for Medium-Range Weather Forecasts (ECMWF) (White 2002) to track different meteorological parameters for the entire atmosphere along individual trajectories. Because we are interested specifically in atmospheric moisture, we used the specific humidity interpolated to the different positions in each trajectory at given times.

To determine the trajectory of each particle, the atmosphere was divided equally into a large number of particles at the start of the model run. These particles each had a constant mass and were distributed homogeneously throughout the atmosphere in proportion to the distribution of atmospheric mass. They were advected according to operational 3-dimensional (3D) ECMWF winds. To calculate both the grid-scale advection and the turbulent and convective transport of the particles, operational ECMWF data were also used as inputs to the model. The positions and specific humidity values $(q)$ were interpolated temporally from the ECMWF data. The increase $(e)$ and decrease $(p)$ in moisture along the trajectory of each particle was calculated by using the rate of change of $q$ over time $(t)$, i.e. $e-p=$ $\mathrm{m} \cdot \mathrm{d} q / \mathrm{d} t$, where $m$ denotes the mass of a particle. By summation of $e-p$ for all the particles in an atmospheric column over a given area, we obtained the quantity $E-P$, which represents the surface freshwater flux, and the individual elements $E$ and $P$ are, respectively, the rates of evaporation and precipita- tion per unit area. By using a Lagrangian approach, it is also possible to track the values of $E-P$ for any specific region backwards in time along a number of trajectories, by selecting those particles that reach the target region at the time of interest.

To ensure an exact mass balance, vertical wind is calculated by using spherical harmonics as part of the data retrieval procedures at ECMWF. To account for turbulence, the FLEXPART model calculates the trajectory of the particles by using the analysed winds plus randomised motion. In the planetary boundary layer (PBL), the random motions are calculated by solving the Langevin equations for Gaussian turbulence (Stohl \& Thomson 1999). The height of the PBL may be determined by using a combination of the Richardson number and the lifting parcel technique (Vogelezang \& Holtslag 1996); the turbulence above the PBL is assumed to be very small. Although global data sets cannot resolve individual convective cells, they can reproduce the large-scale effects of convection. According to Stohl \& James (2004), the limitations of the method are related mainly to the fact that the fluctuations in $q$ that occur along individual trajectories also occur for numerical reasons (e.g. because of the interpolation of $q$ or because of errors in the trajectory concerned). Such numerical noise is partly mitigated by the large numbers of particles present in a given atmospheric column.

We herein describe our use of the tracks of 1.3 million particles over a $5 \mathrm{yr}$ period (data set covers the period from January 2000 to December 2004), which were computed with the ECMWF operational analysis that was available at intervals of $6 \mathrm{~h}$ (00:00, 06:00, 12:00 and 18:00 $\mathrm{h} \mathrm{UTC)}$ at a resolution of $1^{\circ} \times 1^{\circ}$ in latitude and longitude for all 60 model vertical levels. Based on the results provided by Chen et al. (2009), the analysis of the retrotrajectories of $E-P$ was performed for 13 different regions of China (Fig. 1), each of which was characterised by a different regime of precipitation. According to Chen et al. (2009), the regimes of precipitation associated with these 13 modes together explain $45 \%$ of the variance in the monthly precipitation data used in their study, and in Fig. 1 the regions are ordered according to the percentage of variance that is explained by each respective mode. Following the recommendations of Stohl \& James (2005), we limited the transport times to $10 \mathrm{~d}$. Stohl \& James (2005) contended that $10 \mathrm{~d}$ is the average residence time of water vapour in the atmosphere, in agreement with Numaguti (1999).

The analyses focused on the extended summer season (from April to September). To identify the drier and wetter years of the period in question, we used 


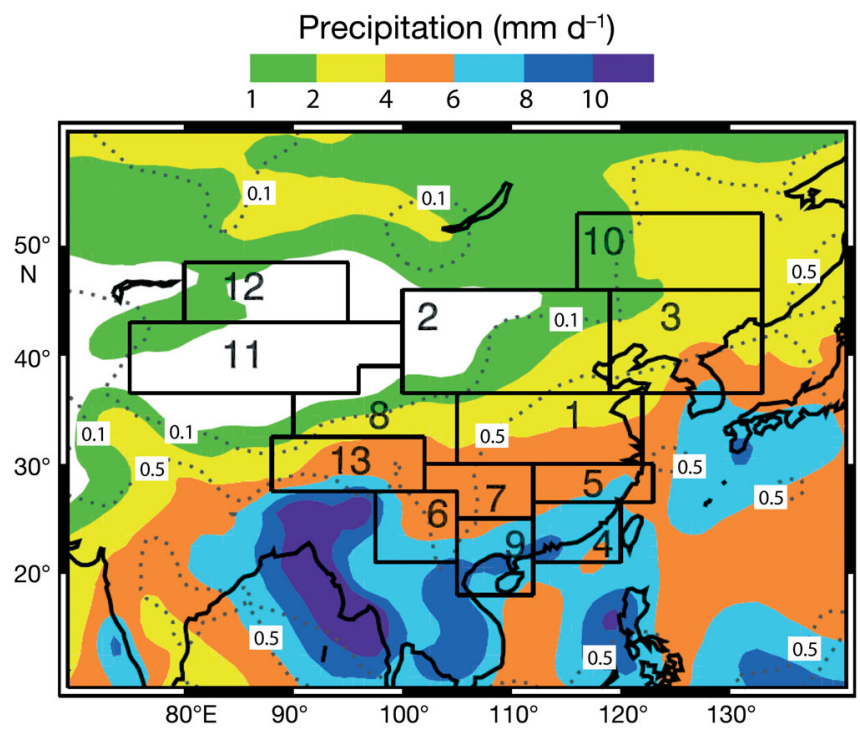

Fig. 1. Rate of precipitation for the extended summer season for April-September 2000 to 2004 (coloured areas, values expressed in $\mathrm{mm} \mathrm{d}^{-1}$; white areas: $<1 \mathrm{~mm} \mathrm{~d}^{-1}$ ) and its interannual variance (grey dotted contours of 0.1 and $0.5 \mathrm{~mm}^{2} \mathrm{~d}^{-2}$ ). Boxes indicate the regions of China selected for the calculation of the backward trajectories of evaporation minus precipitation rates $E-P$ : (1) the Yellow-Huai River basin; (2) Hetao area and northern China; (3) southern portion of northeastern China; (4) southeast coast of China; (5) south of the Yangtze River; (6) Yunnan; (7) Hunan and Guizhou; (8) Qinghai; (9) Guangxi; (10) northern portion of northeastern China; (11) south of Xinjiang; (12) north of Xinjiang; (13) Tibet

data from the Global Precipitation Climatology project v. 2 (Huffman et al. 2001), which were available at daily intervals and at a horizontal resolution of $1^{\circ}$. We calculated the average rate of precipitation for the extended summer in each year in each of the 13 regions. For each region, we selected those years that had the highest and lowest rates of precipitation, hereafter referred to as the wetter and drier years, respectively. To assess the potential implications of any changes in the sources of moisture (in location and/or intensity) for a given target region, we also obtained the $5 \mathrm{yr}$ average summer values of $E-P$. It is important to stress that all the air masses identified in the target region during the selected periods, even ones that were nonprecipitating, were tracked backwards and included in our analysis.

We present herein the values of $E-P$ integrated over a $10 \mathrm{~d}$ period (from the first $10 \mathrm{~d}$ of the trajectory). The resulting fields can be interpreted to be the net gains or losses of moisture in a region during the previous $10 \mathrm{~d}$, and we can use this information to identify the sources of moisture within those regions in which the evaporation exceeded the precipitation over the $10 \mathrm{~d}$ period. Despite the relative complexity of the tracking method, the interpretation of the resulting patterns is straightforward. Therefore, we can track the air masses residing over the target region back in time to see where the moisture originated. Results corresponding to regions characterised by $E-P>0$, where evaporation dominated over precipitation (see Fig. 3, reddish colours in right panels), indicate that air particles located within that vertical column and in transit to the analysed area gain moisture in a backward trajectory. These regions are therefore identified as moisture source regions. It is important to emphasise that we define the 'moisture source region' as an area in which an air parcel absorbed significant amounts of moisture before reaching the atmosphere over the target. Otherwise, $E-P<0$ reveals regions where precipitation dominates over evaporation (see Fig. 3, bluish colours in right panels). Consequently, air masses located over these regions in transit to the analysed area in a backward trajectory display a net loss of moisture, and these regions are identified as moisture sink. It is nevertheless understood that part of the uptake of moisture from the source regions can fall as precipitation along the trajectories of the air masses as they move towards the target area. In the same way, those regions that have a net negative value of $E-P$ can still act as significant sources of moisture for the target area on some of the $10 \mathrm{~d}$ under consideration.

The difference between the $500 \mathrm{hPa}$ seasonal omega observed during the wetter and drier years was also derived as an indicator of a possible increase in rising movements during wetter periods. The monthly values of omega were obtained from the ERA-Interim project (Simmons et al. 2007) at a horizontal resolution of $1^{\circ}$. The monthly data on the vertically integrated moisture flux used to illustrate the characteristics of the dominant circulation over Asia during the extended summer was a product of the National Centers for Environmental Prediction and National Center for Atmospheric Research (NCEP/ NCAR) Reanalysis (obtained from www.cgd.ucar.edu/ cas/catalog/newbudgets/index.html\#Sec11). The topography data set from NCEP/NCAR Reanalysis was also used to show the profile of the Tibetan Plateau in the panels.

\section{RESULTS}

From the distribution of 2000-2004 summer precipitation shown in Fig. 1 we see that the highest values (and higher interannual variability) are observed over southeastern Asia, while the lowest rates oc- 
Table 1. Rates of precipitation $\left(\mathrm{mm} \mathrm{d}^{-1}\right)$ of the extended summer averaged for each of the target regions (R) shown in Fig. 1. Text in bold and italics indicates highest and lowest values, respectively, for each region

\begin{tabular}{|llllllllllllll|}
\hline Year & R 1 & R 2 & R 3 & R 4 & R 5 & R 6 & R 7 & R 8 & R 9 & R 10 & R 11 & R 12 & R 13 \\
\hline 2000 & 3.88 & 1.20 & 3.24 & 6.96 & 5.86 & 6.14 & 4.99 & 2.07 & 6.37 & 2.01 & 0.50 & 0.87 & $\mathbf{5 . 2 0}$ \\
2001 & 2.95 & 1.18 & 3.04 & $\mathbf{8 . 5 7}$ & 5.74 & $\mathbf{6 . 8 1}$ & 4.36 & 2.23 & $\mathbf{8 . 5 8}$ & 1.90 & 0.42 & 0.94 & 4.86 \\
2002 & 3.64 & 1.35 & 3.27 & 7.01 & $\mathbf{6 . 8 7}$ & 6.26 & $\mathbf{5 . 7 7}$ & 2.06 & 7.66 & 2.22 & 0.63 & $\mathbf{1 . 0 5}$ & 4.61 \\
2003 & $\mathbf{4 . 5 0}$ & $\mathbf{1 . 7 9}$ & $\mathbf{3 . 9 4}$ & 5.77 & 4.61 & 5.17 & 4.50 & $\mathbf{2 . 4 4}$ & 6.64 & $\mathbf{2 . 7 4}$ & $\mathbf{0 . 7 0}$ & 1.01 & 4.84 \\
2004 & 3.68 & 1.52 & 3.75 & 5.49 & 5.44 & 6.60 & 5.01 & 2.23 & 6.40 & 2.19 & 0.52 & 0.88 & 4.76 \\
\hline
\end{tabular}

curred over northwestern China. Table 1 shows the average rates of summer precipitation for each of the 13 regions over the period. The variations in precipitation between regions and years are considerable, which is in accordance with the findings of Chen at al. (2009). During 2001, for example, drought conditions predominated in northern China (the lowest rates of precipitation registered in Regions 1, 2, 3, 7, 10 \& 11), while wetter conditions were experienced in southern China (the highest rates of precipitation registered in Regions 4, 6 \& 9). In contrast, wetter conditions prevailed in northern China during the extended summer of 2003 (the highest rates of precipitation registered in Regions 1, 2, 3, 8, 10 \& 11).

The seasonal average vertically integrated moisture flux, together with its divergence for the extended summer of 2000-2004, reveals a region of convergence of flux of moisture over southern Asia that is probably associated with the Eastern Asian Monsoon, and this extends over the east coast of China (Fig. 2). A southwesterly flux of moisture prevails over southern and central China, while a westerly flux of moisture is dominant over northern China.

The results of our analysis of the sources of moisture for the drier and wetter years for all the selected regions are shown in Fig. 3 (left-hand panels) together with the 5 yr summer average values of $E-P$ (right-hand panels). The left-hand panels show the $0.01 \mathrm{~mm} \mathrm{~d}^{-1}$ (solid lines) and $0.3 \mathrm{~mm} \mathrm{~d}^{-1}$ (dotted lines) contours of $E-P$ for the years shown at the bottom of each panel. These contour-line values correspond to the lowest and the highest positive thresholds plotted in the $5 \mathrm{yr}$ average values of $E-P$ in order to better elucidate possible differences from the 'climatological' fields (right-hand panels). The blue lines correspond to the wetter year and the red lines to the drier year in each case.

According to Chen et al. (2009), Region 1 covers a total of 3 valleys, i.e. those of the middle to lower reaches of the Yellow River, the Huai River, and the Hanshui River (Fig. 1). The average precipitation exceeds $3.5 \mathrm{~mm} \mathrm{~d}^{-1}$ in summer (Table 1). The terrain of the region is complex, and flooding generally occurs after heavy rainfall. The 5 yr summer average values of $E-P$ (Fig. 3b) suggest the importance of local evaporation as a source of moisture, which is probably related to the recycling process, as well as the contribution of moisture from southeastern and eastern China and from the South China Sea to Region 1; the reddish colours in Fig. 3 indicate the areas in which $E-P>0$, which are considered to be sources of moisture. By comparing the wetter and drier years (Fig. 3a), it appears that the main differences are in the spatial extension of the source towards southern Asia during the wetter year. The predominance of more negative values of omega in Region 1 during the wetter year (the grey colour in the left-hand panels of Fig. 3 indicates those regions where the difference in the observed $500 \mathrm{hPa}$ omega between the wetter and drier years is negative) suggests that stronger upward movements were experienced in Region 1 in this case.

Region 2 includes the west-central Nei Mongol Autonomous Region, northern Shanxi Province, most of Hebei Province, parts of Gansu Province, and the Ningxia Hui Autonomous Region (Fig. 1). According to Chen et al. (2009), this is a dry region with an average summer rainfall of less than $1.5 \mathrm{~mm} \mathrm{~d}^{-1}$ (Table 1), and the main rainy season occurs in July and August. The 5 yr summer average values of $E-P$ (Fig. $3 d$ ) also show the importance of the target region as a source of moisture, as well as the contribution of moisture from eastern China and from a corridor that extends from the Caspian Sea towards the region. A comparison between the wetter and drier years (Fig. 3c) shows that the main differences may be seen to lie in the spatial extension of the source towards the Caspian Sea during the wetter year. The predominance of more negative values of omega was also observed in Region 2 during the wetter year, which suggests an increase in upward movements in the region in this case.

Region 3 contains the provinces of Liaoning and Jilin (Fig. 1), and its average summer rate of precipi- 


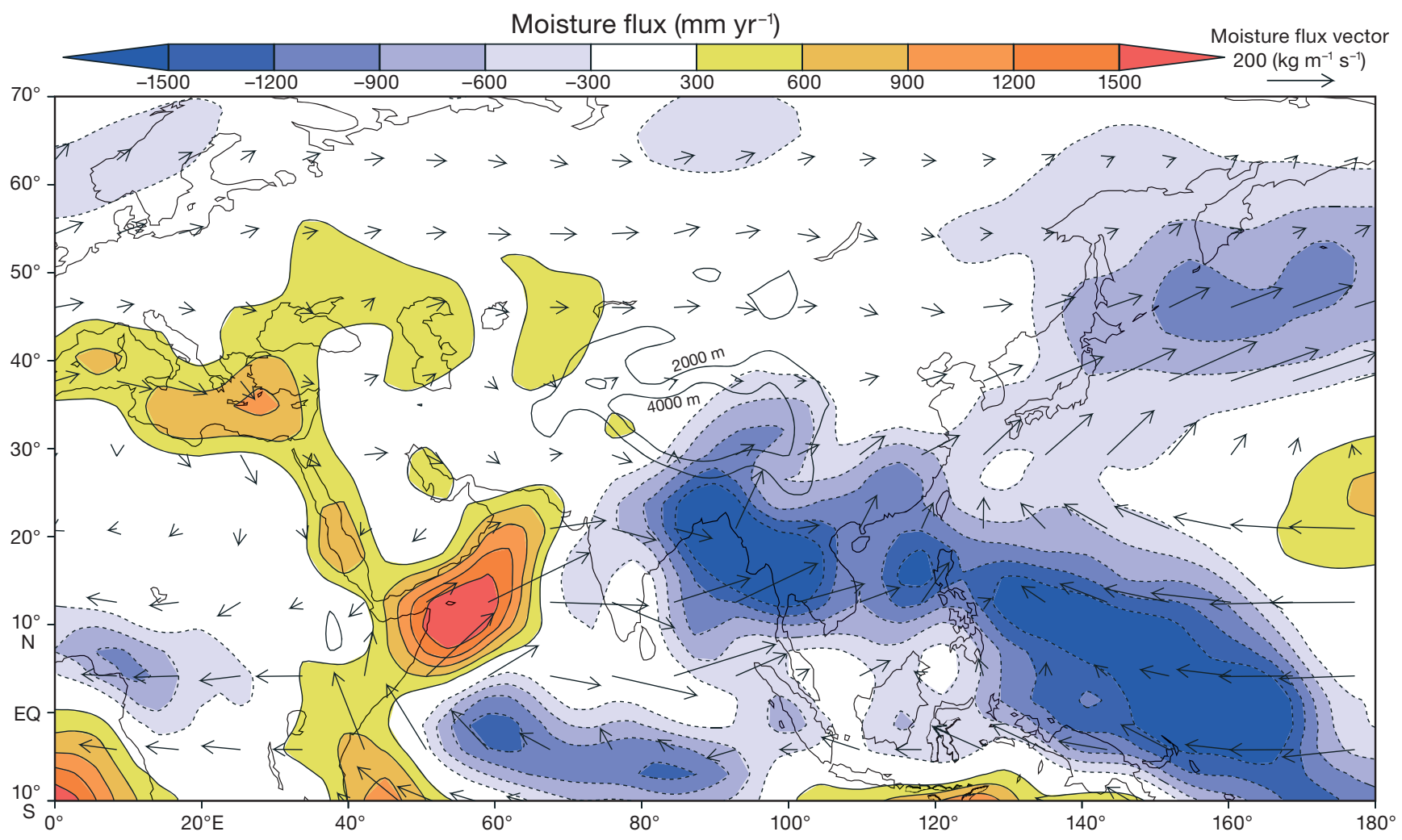

Fig. 2. The vertically integrated flux of moisture and its divergence for the extended summer season (April-September) for the period from 2000 to 2004 . Vectors of moisture flux are expressed in $\mathrm{kg} \mathrm{m}^{-1} \mathrm{~s}^{-1}$, and contours of divergence of moisture flux are

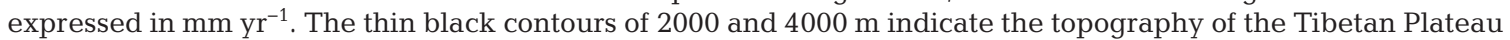

tation is about $3.5 \mathrm{~mm} \mathrm{~d}^{-1}$ (Table 1). The $5 \mathrm{yr}$ summer average values of $E-P$ (Fig. 3f) reveal the importance of region in providing moisture and the contribution of the adjacent areas, particularly of eastern China, the East China Sea and the Sea of Japan. The main difference between the wetter and drier years (Fig. 3e) is a slight westward extension of the eastern Asian source of moisture, and this is associated with the predominance of more negative values of omega in Region 3 during the wetter year.

In southern China, Region 4 encompasses most of the provinces of Guangdong and Fjuian, together with the southern part of Jiangxi (Fig. 1). It has one of the highest rates of precipitation in China, with a summer average of about $6.7 \mathrm{~mm} \mathrm{~d}^{-1}$, as well as a high degree of interannual variation (Table 1). The main rainy season can be divided into 2 periods: the early rainy season (from March to June), which is caused by the monsoon system, and the late rainy season (from July to September), which is caused by the tropical cyclone system (Chen et al. 2009). Before the onset of the South China Sea monsoon (middle May in climatology), the main type of rain in southern China is persistent rainfall in early spring (Wan \&
Wu 2007, Wu et al. 2007). After that period rainfall is caused by the monsoon system and tropical cyclone. The $5 \mathrm{yr}$ summer average values of $E-P$ (Fig. $3 \mathrm{~h}$ ) highlights the contributions of moisture from the East and South China seas and the Bay of Bengal. A comparison between the wetter and drier years (Fig. 3g) shows that the main differences consist of an expansion of the source from the East China Sea. Analysis of the omega values shows an increased upward movement over the region during the wetter year.

Region 5 is also in southern China and covers Zhejiang, eastern Hunan and the northern parts of the provinces of Jiangxi and Fujian (Fig. 1). This region has an average rate of precipitation of about $5.7 \mathrm{~mm}$ $\mathrm{d}^{-1}$ in summer (Table 1). The region is characterised by the Meiyu season (Chen et al. 2009) and is affected by the variability of the Meiyu fronts. As a result the region usually suffers both from heavy flooding and from extreme droughts. The 5 yr summer average values of $E-P$ (Fig. $3 \mathrm{j}$ ) reveals the importance of the target region as a source of moisture, together with the contribution of moisture from the East and South China seas. A comparison between the wetter and drier years (Fig. 3i) reveals an exten- 
sion of the source towards the Arabian Sea during the wetter year. The predominance of more negative values of omega is also seen in Region 5 during the wetter year.

In southwest China, Region 6 covers Yunnan Province, which experiences significant amounts of rainfall (Fig. 1). The average rate of precipitation is about $6.2 \mathrm{~mm} \mathrm{~d}^{-1}$ in summer (Table 1). This region is affected by flows of wet, warm air from the southwest (Chen et al. 2009). The 5 yr summer average values of $E-P$ (Fig. 3l) reveal the contribution of the Bay of Bengal and the Arabian Sea, in addition to that of Eastern China. The extension of the source over eastern China during the wetter year is the most evident difference between both cases (Fig. 3k). The negative values evident in the difference between the values of omega suggest that the upward movement of air was increased in the region during the wetter year.

Region 7 contains Guizhou and the western part of Hunan (Fig. 1). The average rate of precipitation is about $4.9 \mathrm{~mm} \mathrm{~d}^{-1}$ in summer (Table 1). Region 7 is affected by eddies from the southwest that are induced by the presence of the Tibetan Plateau (Chen et al. 2009). The 5 yr summer average values of $E-P$ (Fig. 3n) reveal some contribution of the local area as well as of adjacent areas, mainly eastern China, the East and South China seas, and the Bay of Bengal. The sources of moisture from southern Asia are larger during the wetter year (Fig. 3m), and the negative values evident in the differences in omega values suggests an increased upward movement over the region during the wetter year.

In northwestern China, Region 8 contains Qinghai Province and the northwestern part of Sichuan Province (Fig. 1). The average rate of precipitation is about $2.2 \mathrm{~mm} \mathrm{~d}^{-1}$ in summer, which is lower than the rates observed in the southern regions (Table 1). The $5 \mathrm{yr}$ summer average values of $E-P$ (Fig. $3 p$ ) reveal the contribution of the target area in providing moisture to the air masses, in addition to some moisture coming from western Tibetan Plateau. The source from the western Tibetan Plateau was larger during the wetter year (Fig. 3o), and the predominance of increased upward movement in some parts of the region during the wetter year is seen clearly.

In southern China, Region 9 contains the Guangxi Zhuangzu Autonomous Region, Hainan Province and the western part of Guangdong Province (Fig. 1). This is the southernmost region and is characterised by high rainfall (Chen et al. 2009). The average rate of precipitation is about $7 \mathrm{~mm} \mathrm{~d}^{-1}$ in summer (Table 1). The 5 yr summer average (Fig. 3r) shows the contribution of moisture from the South China Sea and from eastern China. The reddish colours over the Bay of Bengal and the Arabian Sea in Fig. 3 suggest that these regions provide some moisture to air masses during their transit towards the target region, but that part of the moisture precipitates when the parcels cross the coastal regions; bluish colours indicate regions where $E-P<0$. By comparing the wetter and drier years (Fig. 3q), the main differences apparently are the result of are a larger source of moisture in eastern China during the wetter year. The predominance of more negative values of omega is also seen in Region 9 during the wetter year.

Region 10 covers Heilongjiang Province and the northern part of the Nei Mongol Autonomous Region (Fig. 1). The average rate of precipitation is about $2.2 \mathrm{~mm} \mathrm{~d}^{-1}$ in summer (Table 1). The $5 \mathrm{yr}$ summer average values of $E-P$ (Fig. 3t) reveal the importance of the target region as a source of moisture, as well as the contribution of moisture from northern China. The source of moisture expanded westwards in the wetter year, and the predominance of increased upward movement in some parts of the region during the wetter year (Fig. 3s) is seen clearly.

In northwestern China, Regions 11 and 12 cover the Xinjiang Uygur Autonomous Region (Fig. 1). Although these regions are drier, northern Xinjiang (Region 12) experiences more precipitation than southern Xinjiang (Region 11) during the summer, as indicated by the average rates of precipitation of about 0.9 and $0.5 \mathrm{~mm} \mathrm{~d}^{-1}$, respectively, for these two regions (Table 1). The $5 \mathrm{yr}$ summer average values of $E-P$ (Fig. $3 \mathrm{v}, \mathrm{x})$ show the importance of the target areas to the provision of moisture to these 2 regions, as well as the contribution of the adjacent areas that lie to the west of the regions, particularly to southern Xinjiang. Greater differences between the selected years are apparent in the westward expansion of sources of moisture for northern and southern Xinjiang during wetter years (Fig. $3 \mathrm{u}, \mathrm{w}$ for southern and northern Xinjiang, respectively). However, the grey shaded areas in southern Xinjiang (Fig. 3) suggest more favourable conditions to rising movements of air for wetter conditions in this region.

Region 13 includes Tibet and the western parts of the province of Sichuan (Fig. 1) and has an average rate of precipitation of $4.8 \mathrm{~mm} \mathrm{~d}^{-1}$ in summer (Table 1). The 5 yr summer average (Fig. 3z) reveals the contribution of the Bay of Bengal and the Arabian Sea. Both of these moisture sources were more extensive during the wetter year (Fig. 3y), which may be associated with increased rising movements of air over the target area compared with the drier year. 

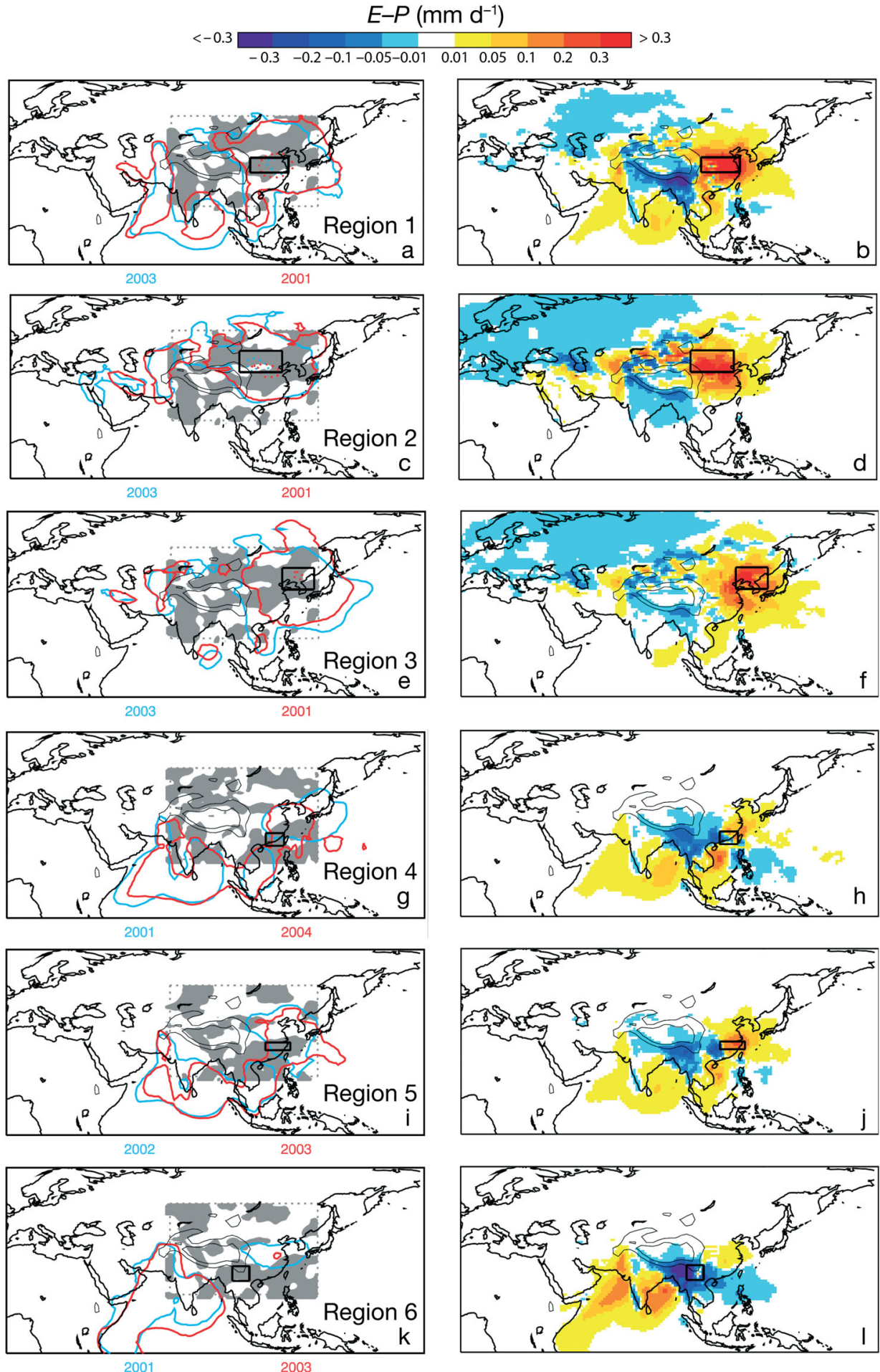

Fig. 3. Left: backward analysis of trajectories for each of the regions shown in Fig. 1 for the extended summer, using $10 \mathrm{~d}$ retrointegrated average values of $E-P$ showing contours of $0.01 \mathrm{~mm} \mathrm{~d}^{-1}$ (solid lines) and $0.3 \mathrm{~mm} \mathrm{~d}^{-1}$ (dotted line), observed for the selected wetter (blue lines) and drier (red lines) years (indicated below each panel). The areas shaded in grey indicate those areas where the difference between the seasonal $500 \mathrm{hPa}$ omega in the selected wetter and drier years is negative. Right: extended summer $10 \mathrm{~d}$ retrointegrated average values of $E-P\left(\mathrm{~mm} \mathrm{~d}^{-1}\right)$ for $2000-2004$. The black boxes indicate the regions analysed in each panel and all panels show the thin black contours of 2000 and $4000 \mathrm{~m}$ representative of the topography of the 


\section{$E-P\left(\mathrm{~mm} \mathrm{~d}^{-1}\right)$}

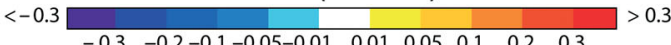
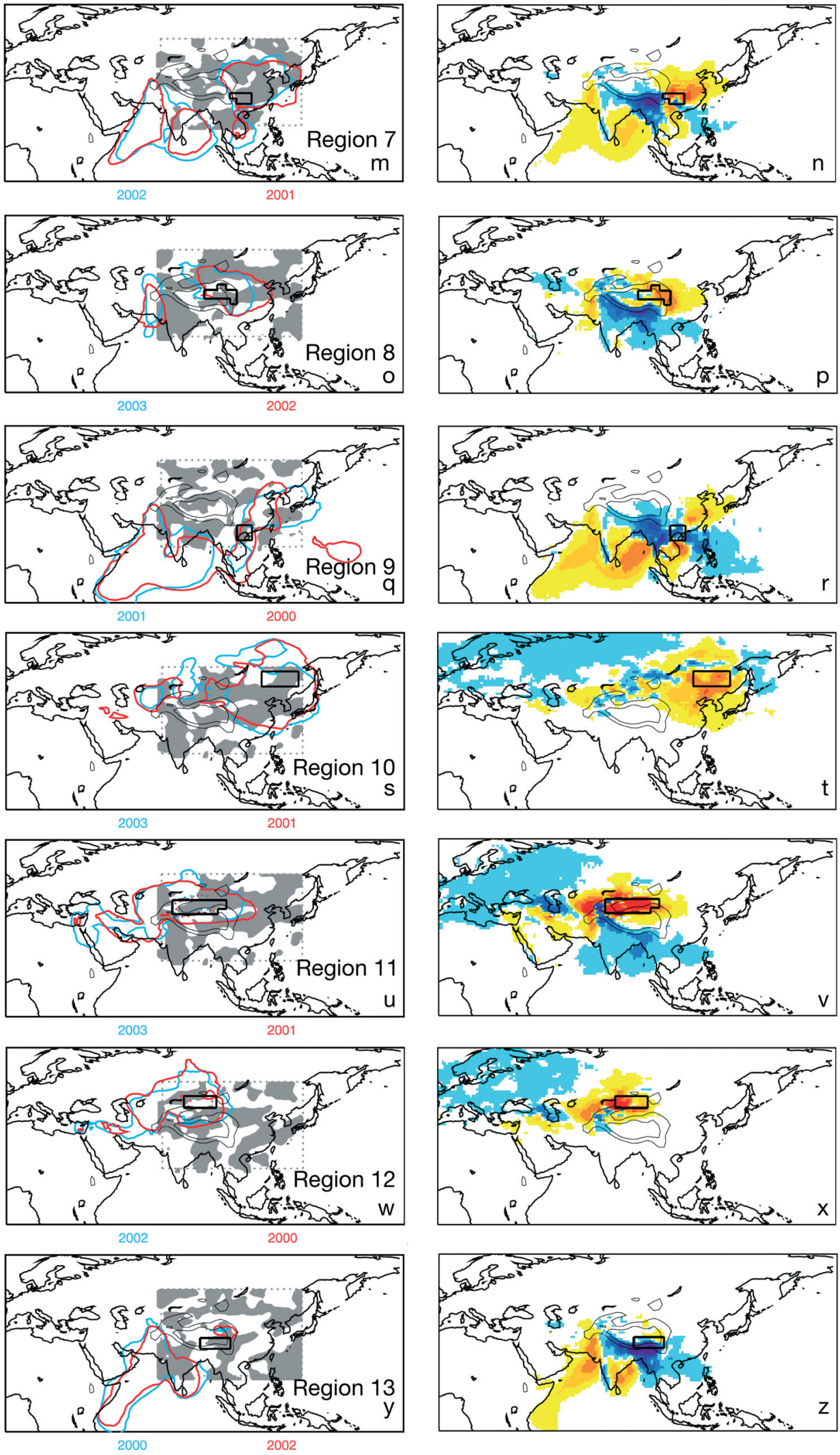


\section{CONCLUSIONS}

Using data obtained from the Lagrangian FLEXPART model for the period from 2000 to 2004, our aim was to provide an overview of the sources of moisture that affect the major regimes of precipitation in China during the extended boreal summer (from April to September) together with some indication of the variations in these sources between drier and wetter conditions.

Our results show that there are several regions that act as sources of moisture for precipitation in China, and that the relative importance of each varies according to the regime of precipitation in question. The results suggest that the evaporation from the target area itself is very important in many regions, and, in general, the contributions of moisture from the East and South China seas are important for the eastern and southeastern coastal regions, while the Arabian Sea and the Bay of Bengal play important roles as sources of moisture for the southern and central regions. Moreover, the northern regions receive some moisture from western Asia. Through our analysis of the contributions of the sources in wetter and drier years in each case, we found that in general, those target regions dominated by moisture from nonlocal sources have a higher variability in terms of the spatial structures of these sources, whereas in those target areas that are characterised by the predominance of local evaporation of moisture there is a lower variability of the distribution of the sources. Even in those cases where the source of moisture for the wetter conditions was quite similar to (or even less extensive than) the equivalent source for drier conditions, there was a more unstable atmosphere in wetter years according to the analysis of the values of omega.

It is important to stress that for the complete analysis of the contrasts between wetter and drier conditions, we only carried out a qualitative comparison between the results without providing any specific quantification of the variations in the contributions made by the sources of moisture. A dynamic analysis could provide a better understanding of these contributions. A 20 yr FLEXPART experiment is currently underway, which should permit studies at the appropriate climatological scale and should allow the investigation of interannual variability, including the impact of various different climatic modes.

Acknowledgements. We are grateful to A. Stohl for providing data on the trajectories of the sources of moisture. The study described herein was supported by the Spanish Ministry of Science and Innovation (MCINN) under grant nos. CGL2008-05968-C02-02 and CGL2008-05968-C02-01 (MSM). This work was partially supported by Xunta de Galicia under Programa de Consolidación e Estruturación de Unidades deInvestigación (Grupos de Referencia Competitiva) funded by European Regional Development Fund (FEDER). The constructive comments of the anonymous reviewers are gratefully acknowledged.

\section{LITERATURE CITED}

Bosilovich MG, Sud YC, Schubert SD, Walker GK (2003) Numerical simulation of the large-scale North American monsoon water sources. J Geophys Res 108:8614. doi: 10. 1029/2002JD003095

Brubaker KL, Entekhabi D, Eagleson P (1993) Estimation of continental precipitation recycling. J Clim 6:1077-1089

Chen TC, Pfaendtner J, Weng SP (1994) Aspects of the hydrological cycle of the ocean-atmosphere system. J Phys Oceanogr 24:1827-1833

Chen LJ, Chen DL, Wang HJ, Yan JH (2009) Regionalization of precipitation regimes in China. Atmos Ocean Sci Lett 2:301-307

China Meteorological Center (1979) Climatological atlas of the People's Republic of China. China Atlas Press, Beijing

Crimp SJ, Mason SJ (1999) The extreme precipitation event of 11 to 16 February 1996 over South Africa. Meteorol Atmos Phys 70:29-42

Ding YH (1992) Summer monsoon precipitation in China. J Meteorol Soc Jpn 70:373-396

Drumond A, Nieto R, Gimeno L, Ambrizzi T (2008) A Lagrangian identification of major sources of moisture over Central Brazil and La Plata Basin. J Geophys Res 113:D14128. doi:10.1029/2007JD009547

- Eltahir E, Bras RL (1996) Precipitation recycling. Rev Geophys 34:367-378

Fernandez J, Sáenz J, Zorita E (2003) Analysis of wintertime atmospheric moisture transport and its variability over southern Europe in the NCEP-Reanalyses. Clim Res 23: 195-215

Gimeno L, Drumond A, Nieto R, Trigo R, Stohl A (2010) On the origin of continental precipitation. Geophys Res Lett 37:L13804. doi:10.1029/2010GL043712

Gustafsson M, Rayner D, Chen D (2010) Extreme rainfall events in southern Sweden: Where does the moisture come from? Tellus Ser A Dyn Meterol Oceanogr 62: $605-616$

> Huang G, Liu Y, Huang R (2011a) The interannual variability of summer rainfall in the arid and semiarid regions of northern China and its association with the northern hemisphere circumglobal teleconnection. Adv Atmos Sci 28:257-268

Huang R, Chen J, Liu Y (2011b) Interdecadal variation of the leading modes of summertime precipitation anomalies over eastern China and its association with water vapor transport over East Asia. Chin J Atmos Sci 35:589-606 (in Chinese)

> Huffman GJ, Adler RF, Morrissey MM, Curtis S, Joyce R, McGavock B, Susskind J (2001) Global precipitation at one-degree daily resolution from multisatellite observations. J Hydrometeorol 2:36-50

Knippertz P, Martin JE (2005) Tropical plumes and extreme precipitation in subtropical and tropical West Africa: part 1. Moisture transport and precipitation generation. Q J R Meteorol Soc 131:2337-2365 
Lau KM, Yang S (1997) Climatology and interannual variability of the southeast Asian summer monsoon. Adv Atmos Sci 14:141-162

Liu J, Stewart RE (2003) Water vapour fluxes over the Saskatchewan River basin. J Hydrometeorol 4:944-959

Liu Y, Huang G, Huang R (2011) Inter-decadal changes of summer rainfall in eastern China detected by Lepage test. Theor Appl Climatol 106:481-488

Nieto R, Gimeno L, Trigo RM (2006) A Lagrangian identification of major sources of Sahel moisture. Geophys Res Lett 33:L18707. doi:10.1029/2006GL027232

Numaguti A (1999) Origin and recycling processes of precipitating water over the Eurasian continent: experiments using an atmospheric general circulation model. J Geophys Res 104:1957-1972

Qian WH, Qin A (2008) Precipitation division and climate shift in China from 1960 to 2000. Theor Appl Climatol 93:1-17

Qian WH, Chen DL, Zhu Y, Shen HY (2003) Temporal and spatial variability of dryness/wetness in China during the last 530 years. Theor Appl Climatol 76:13-29

Ren H, Zhang P, Chou J, Li W, Gao L (2006) Large-scale lowfrequency rainfall regimes and their transition modes in summertime over China. Chin Sci Bull 51:1355-1367

Ronberg B, Wang WC (1987) Climate patterns derived from Chinese proxy precipitation records: an evaluation of the station networks and statistical techniques. Int J Climatol 7:391-416

Simmons A, Uppala S, Dee D, Kobayashi S (2007) ERAInterim: new ECMWF reanalysis products from 1989 onwards. ECMWF Newslett 110:25-35

Stohl A, James P (2004) A Lagrangian analysis of the atmospheric branch of the global water cycle. Part 1: method description, validation, and demonstration for the August 2002 flooding in central Europe. J Hydrometeorol 5: 656-678

Submitted: March 28, 2011; Accepted: August 14, 2011
Stohl A, James P (2005) A Lagrangian analysis of the atmospheric branch of the global water cycle. Part 2: Earth's river catchments, ocean basins, and moisture transports between them. J Hydrometeorol 6:961-984

Stohl A, Thomson DJ (1999) A density correction for Lagrangian particle dispersion models. Boundary-Layer Meteorol 90:155-167

Sun LH, Zhao ZG, Xu L, Chen G, Li W, Wang Y, Liu H (2005) Study of summer rain pattern in monsoon region of East China and its circulation cause. J Appl Meteorol Sci 16: 56-62 (in Chinese)

Tao SY, Chen LX (1987) A review of recent research of the east Asian summer monsoon in China. In: Chang $\mathrm{CP}$, Krishnamurti TN (eds) Monsoon meteorology. Oxford University Press, Oxford, p 60-92

Trenberth KE (1999) Atmospheric moisture recycling: role of advection and local evaporation. J Clim 12:1368-1381

Trenberth KE, Dai A, Rasmussen RM, Parsons DB (2003) The changing character of precipitation. Bull Am Meteorol Soc 84:1205-1217

Vogelezang DHP, Holtslag AAM (1996) Evaluation and model impacts of alternative boundary-layer height formulations. Boundary-Layer Meteorol 81:245-269

Wan RJ, Wu GX (2007) Mechanism of the spring persistent rains over southeastern China. Sci Chin Ser D Earth Sci 50:130-144

Wang SW, Ye J, Gong D, Chen Z (1998) Study on the pattern of summer rainfall in eastern China. J Appl Meteorol Sci 9(Suppl):65-74 (in Chinese)

White PW (2002) IFS documentation. ECMWF Rep, European Centre for Medium-Range Weather Forecasts, Reading

- Wu G, Liu Y, Zhang Q, Duan A and others (2007) The influence of mechanical and thermal forcing by the Tibetan Plateau on Asian climate. J Hydrometeorol 8:770-789

Proofs received from author(s): November 9, 2011 